\title{
Factors affecting Succession Planning in Small and Medium Enterprises in Kenya
}

\author{
Florence Mutunga \\ P.O. Box 26 - 60100, EMBU, KENYA \\ Email: wanzarattah@yahoo.com

\section{Dr. Hazel Gachunga}

Jomo Kenyatta University of Agriculture and Technology, School of Human Resource Development, P.O. Box 62000 - 00200, NAIROBI, KENYA

DOI: $\quad 10.6007 /$ IJARBSS/v3-i8/143 URL: http://dx.doi.org/10.6007/IJARBSS/v3-i8/143

\begin{abstract}
The main purpose of the study was to investigate the factors affecting Small and Medium Enterprises in Kenya. Specific objects of the study included establishing how nurturing and development is a factor influencing Succession Planning in Small and Medium Enterprises

The study will be significant to the Small and Medium-scale Enterprises, and the government who will appreciate and understand the factors affecting Succession Planning of Small and Medium Enterprises. This will enable policy makers, practitioners and other SMEs stakeholders to identify the factors that affect the growth of the SMEs with a view to understand and appreciate the importance of their services to financing of Small and Medium Enterprises and be able to encourage use of succession plans. It will also provide background information to researchers who may want to carry out further research.
\end{abstract}

The study established that small and medium enterprises have a succession plan, replace the current owner/manager with a successor in good time, plan ahead for succession and customers do find it easy to get used to the new owner. The study recommends a need for the government and SMEs to create an appropriate information base to support and promote SMEs in Succession planning and come up with a follow up policy and mechanism.

Keywords: Human Resource Management, Succession Planning, Small and Medium Enterprises.

\subsection{Introduction}

Small and medium enterprises vary in definition. The Wiltshire Committee's definition of small business is often used by researchers and states that: '...it is a business in which one or two persons are required to make all the critical management decisions such as finance, accounting, personnel, purchasing, processing or servicing, marketing, selling, without the aid of internal specialists and with specific knowledge in only one or two functional areas....' (Berryman, 1983). 
The term SME covers a wide range of definitions and measures, varying from country to country and between the sources reporting SME statistics. In developing countries the number of employees and the size of assets or turnover for SME tend to be much smaller compared to their counterparts in developed countries due to their relative size of business entities and economies (Nation Media and KPMG, 2011).

In Kenya, types of Small Scale Businesses include; survivalist enterprises which are activities by people unable to find a paid job or get into an economic sector of their choice. Micro enterprises are very small business, often involving only the owner, some family member(s) and at the most one or two paid employees. Medium enterprises constitute a category difficult to demarcate vis-a'-vis the 'small' and 'big' business categories. Kenya has about 1.6 million registered small and medium enterprises constituting about $96 \%$ of all business enterprises in the country (KPMG and Nation Media Group, 2004).

A recent survey dubbed, the annual top small and medium enterprises in East Africa that is carried out by audit firm KPMG and Nation Media Group found out that revenue growth was highest in the past 12 months for small businesses in construction at $61 \%$, services $46 \%$ and information technology $44 \%$ - segments of the economy reflecting the intensity of activity in the sectors. Majority of these small and medium enterprises are family owned business units with the family member being the majority shareholders. They are also known for their poor book keeping records and the secrecy in which they conduct their businesses. (KPMG and Nation Media Group, 2004).

Small and Medium Enterprises are generally distinguished by the nature of their production and management arrangements, trading relations, financial practices, and internal competence among others. The major characteristics of small and medium enterprises are:- small units, often rural-based and family-owned; small independent enterprises, standing alone and producing for a well-defined market; specialized firm, producing specialized products, selling to the international and or local markets; rely on low cost raw materials, low energy costs, low labor costs, low division of labor; flexible and often small production runs; low capital formation and largely labor intensive units with low-level technologies; but note the emergence of high skill and technology-intensive small and medium enterprises, especially in high technology industries (World Bank, 2007).

The development of Small and Medium Enterprises has been hindered by political instability or strong dependence on a few raw materials as opposed to a fairly modern financial systems and clear government policies in favor of private enterprise. Small and Medium Enterprises are weak in Africa because of small local markets, undeveloped regional integration and very difficult business conditions, which include cumbersome official procedures, poor infrastructure, dubious legal systems, inadequate financial system and unattractive tax regimes (World Bank, 2007). Many firms stay small and informal and use simple technology that does not require great use of national infrastructure. Their smallness also protects them from legal proceedings so they can be more flexible in uncertain business conditions (MSME Brochure, 2007). 
A family-owned enterprise is a 'total system' that is derived from a number of sub-systems, including the founding entrepreneur as an entity, the family member as an entity and the enterprise as an entity (Dyer and Handler, 1994). Successful succession can provide a familyowned business with a competitive edge over a non-family-owned business by enabling the continued use of accumulated idiosyncratic knowledge of family members (Bjuggrenand Sund, 2001). The inside knowledge possessed by family members, coupled with their loyalty and trust, endows them with specific competencies and know-how required to run the business effectively and helps them to create the resources and capabilities required to generate a competitive advantage (Ram and Jones, 2002). In professionally managed firms, boards of directors often make succession decisions by utilizing a professional recruitment consultancy service. In such firms, the successor is selected from a pool of candidates on the basis of perceived competency.

\subsection{Statement of the Problem}

In family-owned businesses there are a few people in either the business or the family with any experience of when and how succession should be dealt with, as this issue is a rare event for the family firm occurring only once for each generation (Fox et al, 1996). Consequently one of the most pressing problems for the family-owned business is planning to pass control of the business to the next generation (Kuratko et al, 1993), with succession a problematic and neglected issue in many family business (Bachkaniwala et al, 2001). Succession planning is an explicit process by which the firm will be transferred to the family's next generation. Whilst the successful succession of CEOs is a crucial goal for these firms, without the next generation's leadership and direct management, the firm cannot survive as a family-owned business let alone maintain its character (Barach \& Ganitsky 1995).

One of the most central problems facing family-owned businesses is the ability to ensure competent family leadership across the generations. Only one third of family businesses survive into the second generation, and only about $10 \%$ to $15 \%$ make it into the third generation (Birley, 1986; Ward, 1987). Poor successions are often the source of the problem (Miller, Steier, \& Le Breton-Miller, 2003).

In family-owned businesses there is often a smaller pool of talent on which to draw, complicating emotional factors in the incumbent-successor relationship, and complex social ties with the family (Dyer, 1986; Lansberg, 1999; Miller, Steier, \& Le Breton-Miller, 2003). According to the Kenya National Bureau of Statistics, 2007; three out of five businesses fail within the first few months of engagement. Data on the Micro, Small and Medium Enterprises sector in Kenya is scarce. The National Small and Medium Enterprises Baseline Survey provides comprehensive and reliable information, it has not been updated since 1999 and does not contain information on Succession Planning for Medium-sized firms. 


\subsection{Literature review}

\subsection{Theoretical Review}

Succession Planning is a process where firms plan for the future transfer of ownership. In fact, it occurs when the firm owner wishes to exit from the firm nevertheless wants the business to continue. The motive behind this is to transfer ownership of the firm to any of the family members rather than shutting down the business altogether. Succession planning is generally considered to be a unique, case-by-case process, where a one-size-fits-all mentality is simply not appropriate (Sambrook 2005).

\section{Conceptual Framework}

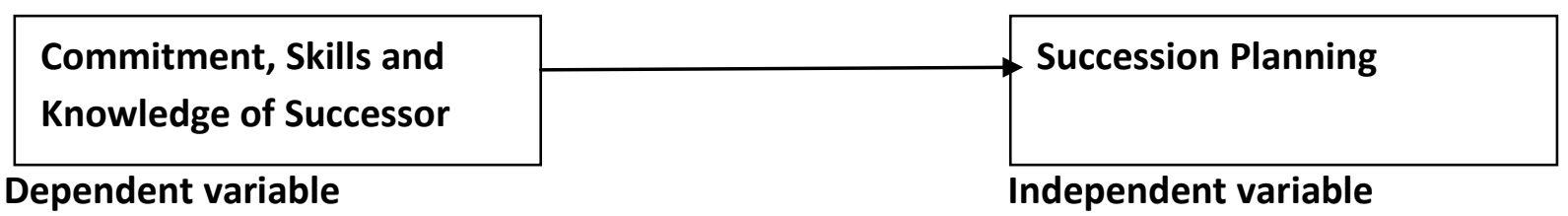

\subsection{Commitment, Skills and Knowledge of Successor}

The two conditions, which are crucial for the succession to proceed as intended, are the successor's willingness to demonstrate a long-term commitment to the business and his or her ability to gain the necessary knowledge, skills, competencies required to manage within the finite time-span leading up to the retirement of the incumbent (Fox et al.,1996).

For most family-owned businesses, predecessors do not wish to contemplate succession because they fear the loss of power and status (Fox et al., 1996). In a case study of six Kenyan firms, Janjuha-Jivraj and Woods (2002) found that for most of the sample firms, with the transition from second to third generation, firms began to work on a formalized succession plan involving both generations. While the first generation owners that developed the business experienced difficulties in relinquishing control, the third generation successors, often educated in foreign countries, allowed the increased employment of non-family staff in their companies, institutionalizing the notion of separating ownership and management. Martin (2001:223), noted that there was the need to 'keep the business in the family' since it is a key determinant for family-run firms globally.

The succession process is only complete when the successor has gained legitimacy and is widely accepted by the stakeholders. Completion of the process is contingent on the successor's ability to exercise appropriate leadership in the business (Fox et al., 1996). The progressive delegation of authority to the successor is essential if the successor is to assume full control. The lack of delegation not only frustrates the learning process of the successor but, perhaps more importantly, it serves to reduce their credibility in the eyes of employees and other key stakeholders (Fox et al., 1996). 


\subsection{Succession Planning}

In small firms it is generally the entrepreneur who is solely responsible for the management of human resource (Matlay,2002; Klaas and Klimchak, 2006). Often because small firms cannot justify full-time human resource professionals due to limited size and resources (Klaas et al, 2000), and still many entrepreneurs do not perceive Human Resource Management in small firm as a very sophisticated process requiring specialist (Pearson et al, 2005; Matlay, 1999). While being small, this task will not present much of a problem for most entrepreneurs. However Mazzarol (2003) states that when a firm grows and it's number of employees increase the complexity of Human Resource Management deepen.

Scholars identify a dearth of research at the intersection of Human Resource Management and Entrepreneurship. According to an editorial to a special issue of Human Resource Management;" Small and Medium-sized Enterprises have been treated as second class citizens by authors in the Human Resource Management literature for too long" (Heneman and Tansky, 2003). This statement is based on finding only 17 articles on Human Resource Management and Small Firms in academic journals between 1984 and 1999. (Reported in Heneman et.al., 2000). Research on Human Resource Management in in small firms focuses on a neglected group of firms and responds to several appeals for more research.

In conclusion Human Resource Management practices in smaller venture (firms with less than 150 employees) have stagnated or even regressed over the last decade despite threats with the regulatory and external environments of small firms that should see a greater emphasis on Human Resource Management in small firms. (Hornsby and Kuratko, 2003). Furthermore, they also found out that in spite of the considerable volume and diversity of Human Resource Management research, relatively little is understood regarding the Human Resources Management related needs, practices, behaviors and outcomes of smaller venture.

\subsection{Critique of the Existing Literature Relevant to the Study}

The Succession Planning literature applied in this research proposal that "A business often owes its success to the drive, vision and creative energy of its owner or owners. When an owner leaves the business, regardless of the reason, it has an impact sometimes an enormous one. Although the job of replacing a creative and visionary owner may be impossible to ease that loss through advanced Succession Planning" (P.Winn, 2000, pg 2). According to Paul, there are four main components to Leadership Succession Planning. The first component is identifying the potential successor; the process of selecting a suitable candidate to take reigns of the business upon the departure of the current CEO begins with the identification of at least one and preferably more than one candidate and should begin as soon as possible and long before the CEO decides to step down.

The second component is changing management style: something that can be both a hallmark and at times can be an identified weakness of many organizations is the CEO's management style. The succession process requires the candidate or candidates to be taught how to lead and manage, the CEO must at times forgo their personal leadership and management style and 
become to teacher and mentor for the candidate. The third component is successor training and development: the principle function of the CEO in helping assure the success of his or her successor lies in the appropriate leadership development of the candidate. The fourth and final component is selecting the successor: there are many factors that will qualify an individual to lead and manage a business. Those factors should include knowledge, skills, abilities, motivation, ambition, temperament, formal education and experience.

The literature on succession process in Family-Owned Businesses' presumes that the eldest sons of owners will be their successors, although attention has been given recently to daughters (Fox et al., 1996). Kuratko et al. (1993) in their study of US and Korean small business owners found that the overwhelming majority wanted a son to take over the firm.

This was the case for both the US and Korean firms. Martin (2001) from a sample of small and medium-size firms found the male offspring were described and treated as 'heirs apparent' this was the case whether or not they were currently employed by the firm. In contrast, Bachkaniwala et al. (2001) from case studies of South Asian Family-Owned Businesses found that the founder chose his eldest son as his successor in only one case. In Kenya, the situation is not different. The World Bank's report argues that 'there are specific legal, regulatory, and administrative barriers that women entrepreneurs face that are either not encountered at all by their male counterparts or have a disproportionate effect on women.

Recently, Sten (2004) found that while the founders of family Small and Medium Enterprises in Finland almost universally desire to pass ownership to their offspring (succession), the latter increasingly desires to be relieved of this pressure and rejoices when the business is sold to outside members (transfer). Sadly for them, the new owners often desire to get rid of every family member and realign the company in a way that changes its culture and nature. These results are consistent with MacWhirter et al. (2004) study for specific cases within the UK. Their study concentrates on the chosen exit strategies of entrepreneurial family firms. They find that both the availability of a willing successor and the specific personal and family values involved have a significant influence on the exit route chosen.

\subsection{Research Design}

Research design it is structure of an enquiry. The use of research design minimized the chance of drawing incorrect causal interference from data. Descriptive survey design was adopted in conducting this study. According to Gary Moon, (1990) a descriptive research is a process of collecting data in order to test hypothesis or to answer questions concerning current status of subjects in the study. The purpose of the descriptive research was to determine and report way things are. It attempts to describe such things as possible behavior, attitudes, values and characteristics. This approach was appropriate for this study because it involves fact finding and enquiries to determine Succession Planning as reflected in Family Owned Businesses.

A population can be defined as including all people or items with the characteristic one wishes to understand. Because there is very rarely enough time or money to gather information from 
everyone or everything in a population, the goal becomes finding a representative sample (or subset) of that population. The target population of this study was drawn from 17,862 medium trader shop or retail services from Nairobi County. The study was intended to focus on Succession Planning in Family-Owned Businesses. According to Saunder et al. (2003) for a population of more than 10,000 a sample size of 385 is a representative. Further we decided to use a sample of businesses that have been in operation for five or more years and had five or more employees. The actual businesses interviewed were arrived at by use of simple random procedure and total of 98 interviews with business owners distributed proportionately will be carried out.

Pilot test is a replica of the main survey. It was carried out on 5 Family-Owned Businesses within the CBD and they were picked randomly from the population. The questionnaires were tested to confirm reliability and validity prior to administering. Reliability is the extent to which results are consistent over time and accurate representation of the total population under study is referred to as reliability and if the results of a study can be reproduced under a similar methodology, then the research instrument is considered to be reliable. Validity determines whether the research truly measures that which it was intended to measure or how truthful the research results are (Joppe, 2000).

\subsection{Data analysis and presentation}

On collection of data, it's important to ensure proper coding before analysis can start. Coding involves assigning numbers to various responses. It was done cautiously to avoid errors. Frequency results was in many cases reveal preliminary problems that must be corrected before any advanced statistical computations are done for example frequencies, percentages, means, modes, medians, standard deviation, variance and correlations. (Mugenda \& Mugenda, 1999). Quantitative data was analyzed using Statistical Package for Social Science (SPSS). The results established the pattern of responses to each of independent variables under investigation.

\subsection{Research Findings and Discussions}

\subsection{Commitment, Knowledge and Skill of Successor}

The study sought to investigate various aspects of commitment, knowledge and skill of Successor and how it impacts on succession planning of SMEs. The following responses were given:

\subsubsection{Business Association}

The study showed the views of the respondents on whether the customers are proudly associated with the business. According to the study the majority of respondents had varied responses as follows: $59 \%$ strongly disagreed to this statement, $34 \%$ were neutral, $3 \%$ agreed and $4 \%$ strongly agreed. From Figure $4-10$ below of the study it can be concluded that in most 
SMEs, the customers are not proudly associated with the business because of lack of customer relation skills.

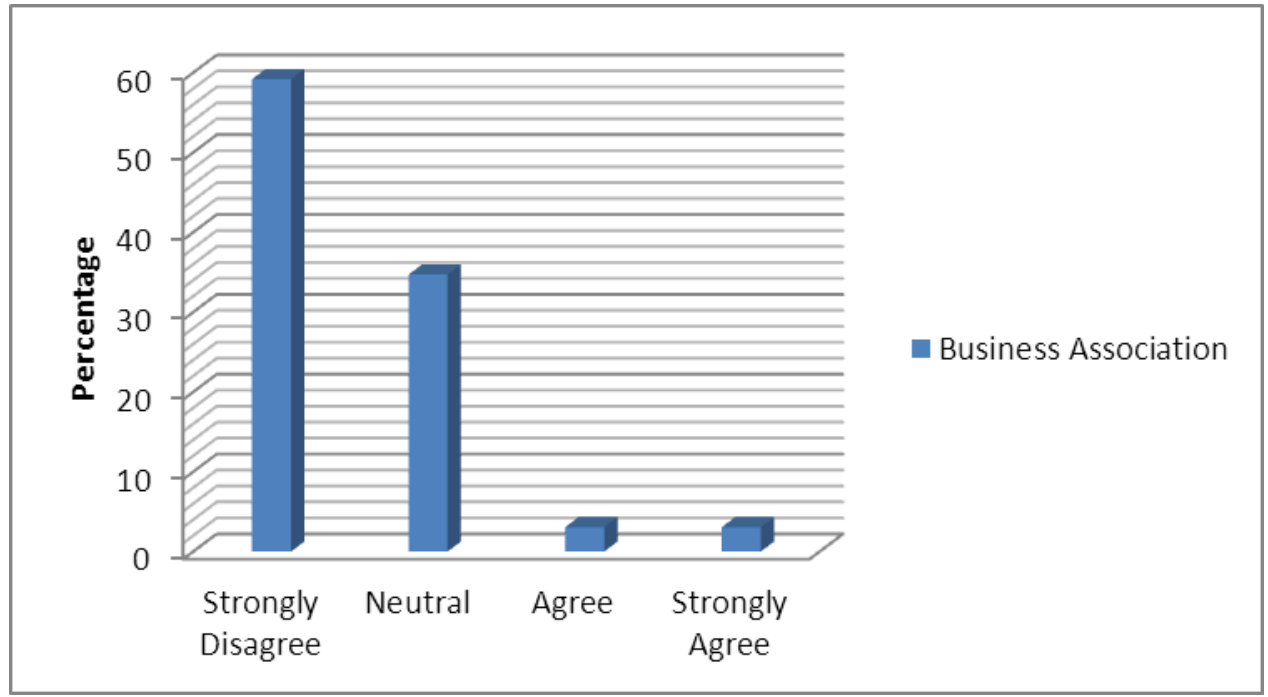

Figure 4 - 1: Business Association

Source: Author (2012)

\subsubsection{Confidence in Other Capabilities}

According to the study $26 \%$ of total respondents, indicated that they had strongly disagreed to the fact that the family members have confidence in each other's business capabilities, 9\% disagreed, 57\% were neutral, 3\% agreed and 5\% strongly agreed. From Figure 4-11 below of the study it can be concluded that the majority of respondents have confidence in each other's business capabilities.

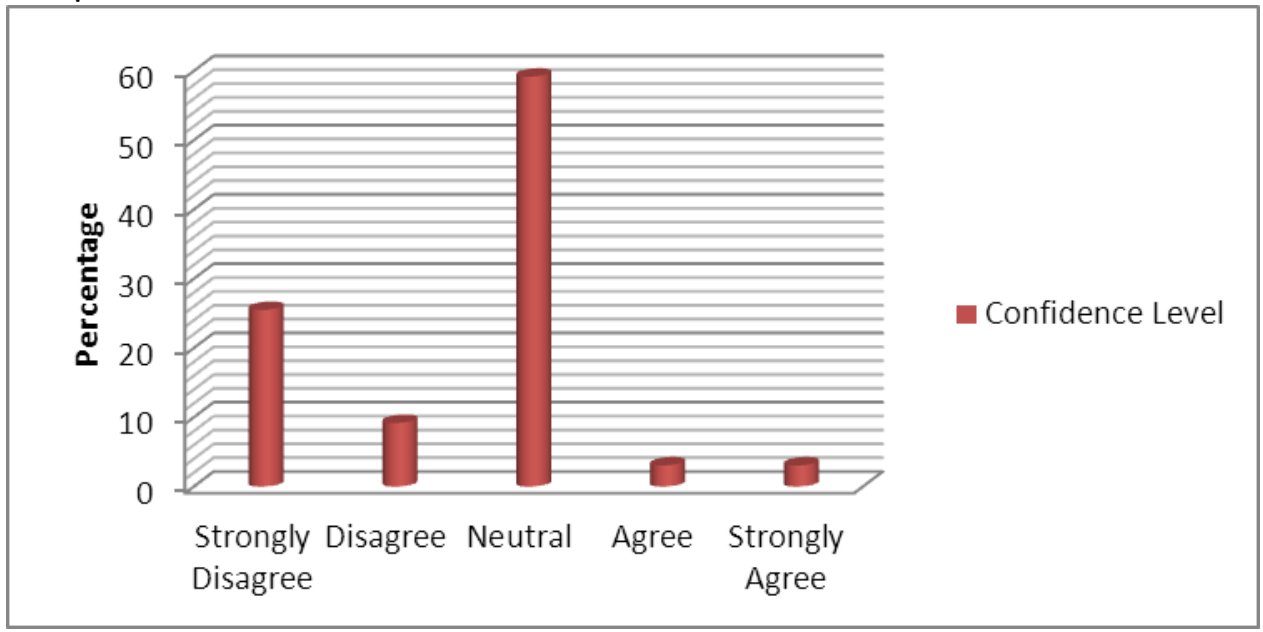

Figure 4 - 2: Confidence in Others Capabilities

Source: Author (2012) 


\subsubsection{Preparation to Take Over}

The study shows the views of the respondents on whether the person who will take over the business when the current owner/manager retires is being prepared for his/her future role. According to the above study $25 \%$ of the respondents strongly disagreed to this statement, $9 \%$ disagreed, 59\% were neutral, 3\% agreed and 4\% strongly agreed. From Figure 4-12 below of the study it can be concluded that most SMEs prepare the person to take over the business when the current one retires.

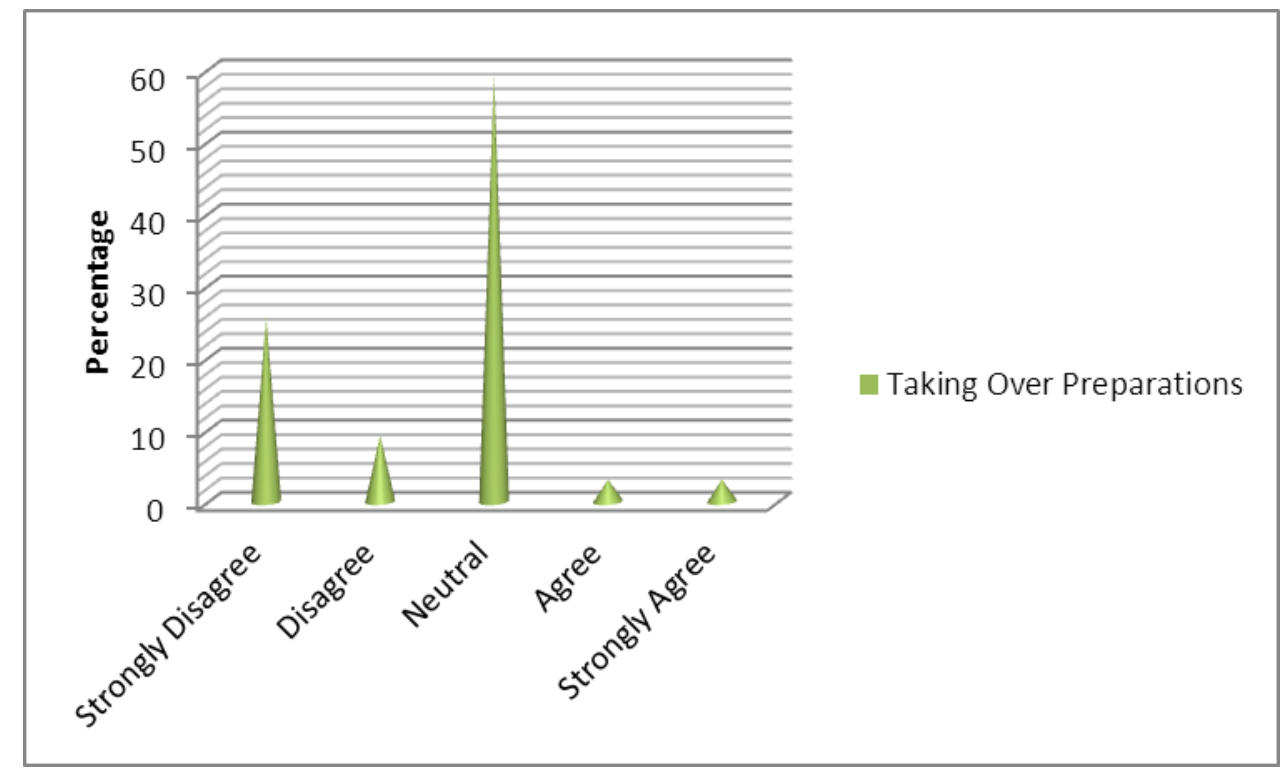

Figure 4 - 3: Preparation to Take Over Source: Author (2012)

\subsubsection{Communication Channel}

According to the study $47 \%$ of total respondents, indicated that they had strongly disagreed to the fact that the communication channels available in the business are adequate, $47 \%$ were neutral, 3\% agreed and 3\% strongly agreed. From Figure 4-13 below of the study it can be concluded that there are inadequate communication channels available in businesses. 


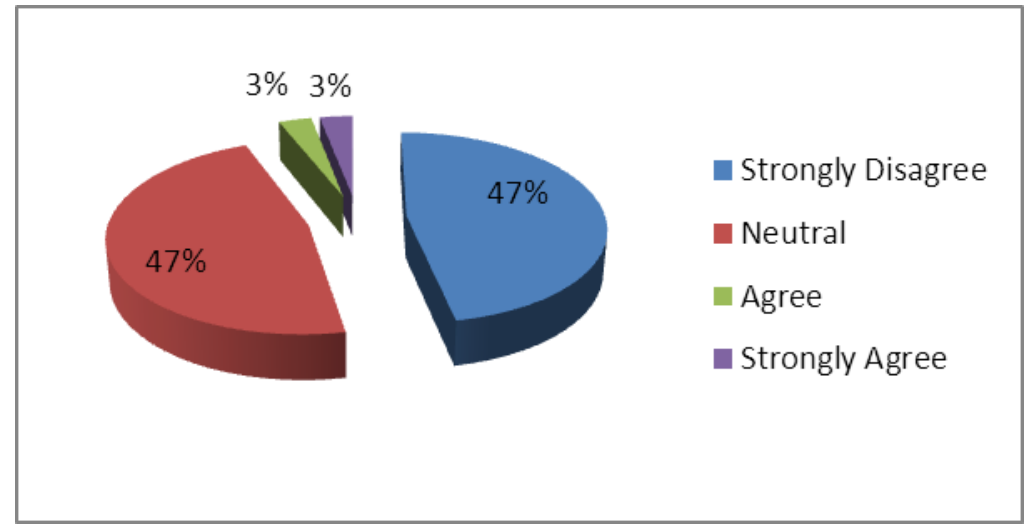

Figure 4 - 4: Communication Channel

Source: Author (2012)

\subsubsection{Business Ambitions}

The above study shows percentage of the people who responded on the question; "I can realize my business ambitions in this business". 57\% strongly disagreed, $32 \%$ were neutral, $5 \%$ agreed and $6 \%$ strongly agreed. From Figure 4-14 it can be inferred that majority of the respondents do realize their business ambitions.

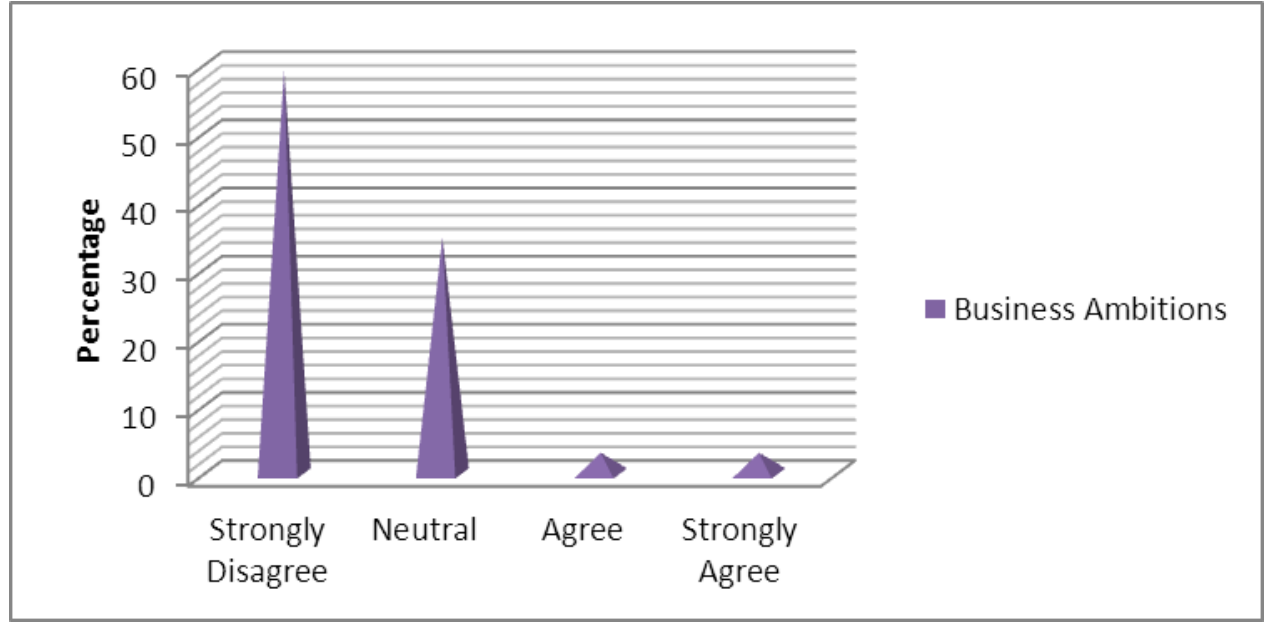

Figure 4 - 5: Business Ambitions

Source: Author (2012)

\subsubsection{Continue Working}

According to the study $44 \%$ of total respondents, indicated that they had strongly disagreed to the fact that even if the employees get an opportunity to leave, they would continue working for the same business they were working for initially, 6\% disagreed, 42\% were neutral, 5\% agreed and 3\% strongly agreed. From Figure 4-15 below of the study, employees cannot be retained to work in the same business they were working for after securing another job elsewhere since personal objectives were not met. 


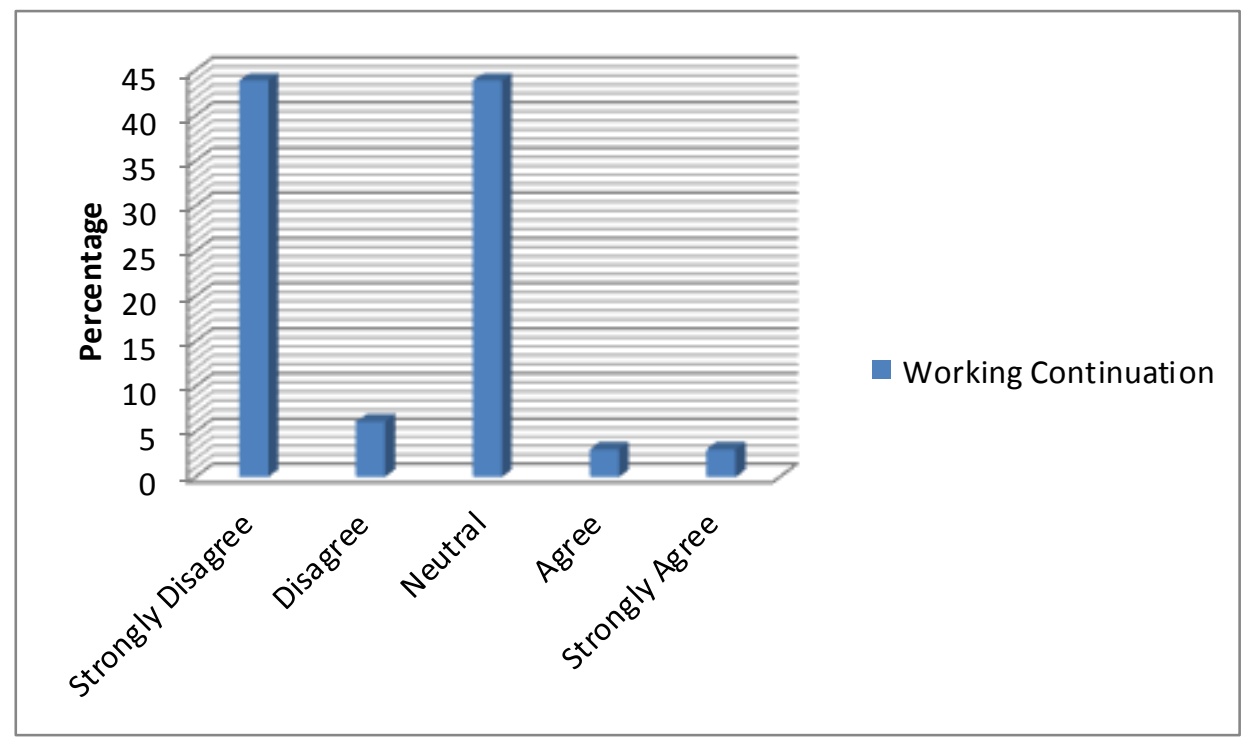

\subsubsection{Rewarding Career}

Figure 4 - 6: Continue Working Source: Author (2012)

The study shows the views of the respondents on whether the employees can have a rewarding career in the same business they were venturing in. According to the above study $56 \%$ of the respondents strongly disagreed to this statement, $13 \%$ disagreed, $23 \%$ were neutral, $3 \%$ agreed and $5 \%$ strongly agreed. From the study it can be concluded that most employees in SMEs do not view the type of business they are involved in as rewarding and hence would not want to venture in the same business in future.

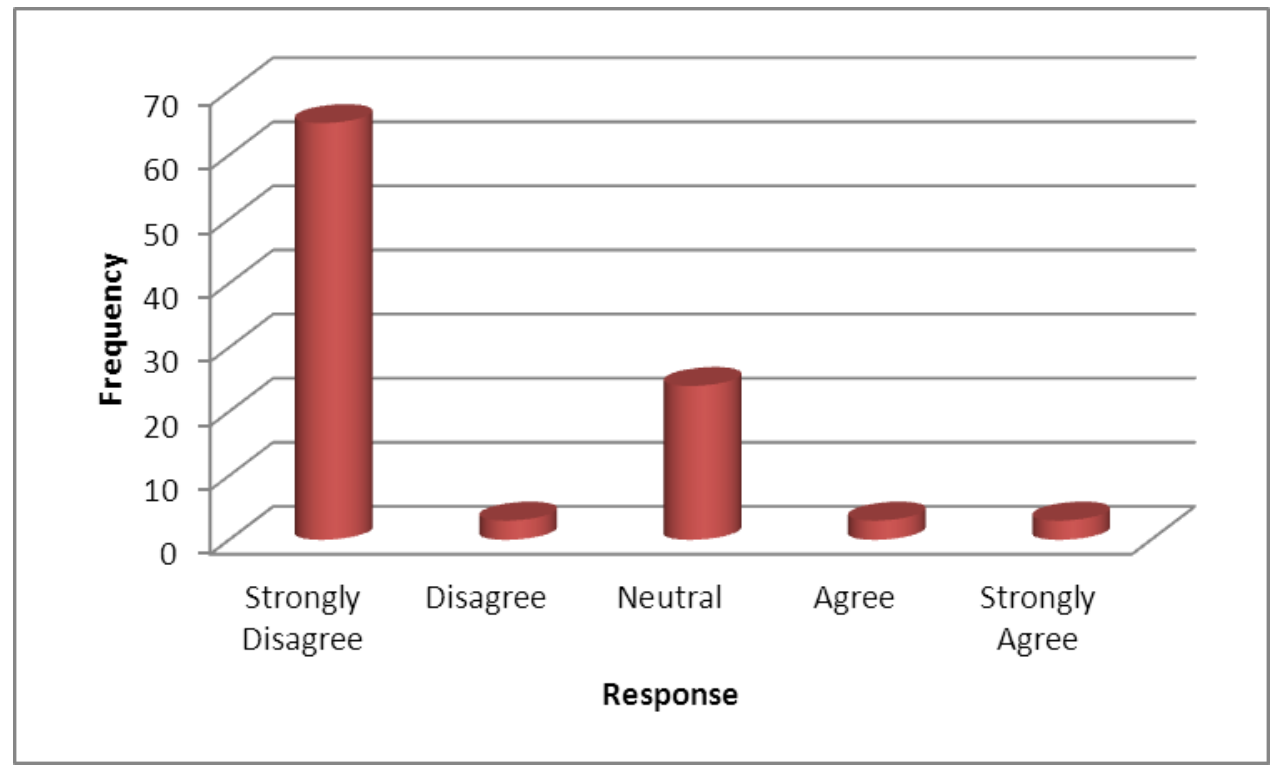

Figure 4 - 7: Rewarding Career

Source: Author (2012) 


\subsubsection{Formal Training}

The study shows the views of the respondents on whether a formal/informal training is determined, fulfilled and tracked early for the new owner/manager. According to the above study $53 \%$ of the respondents strongly disagreed to this statement, $31 \%$ were neutral, $11 \%$ agreed and 5\% strongly agreed. From Figure 4-16 below of the study it can be concluded that there is no formal/informal training offered to new managers prior to undertaking the assignment.

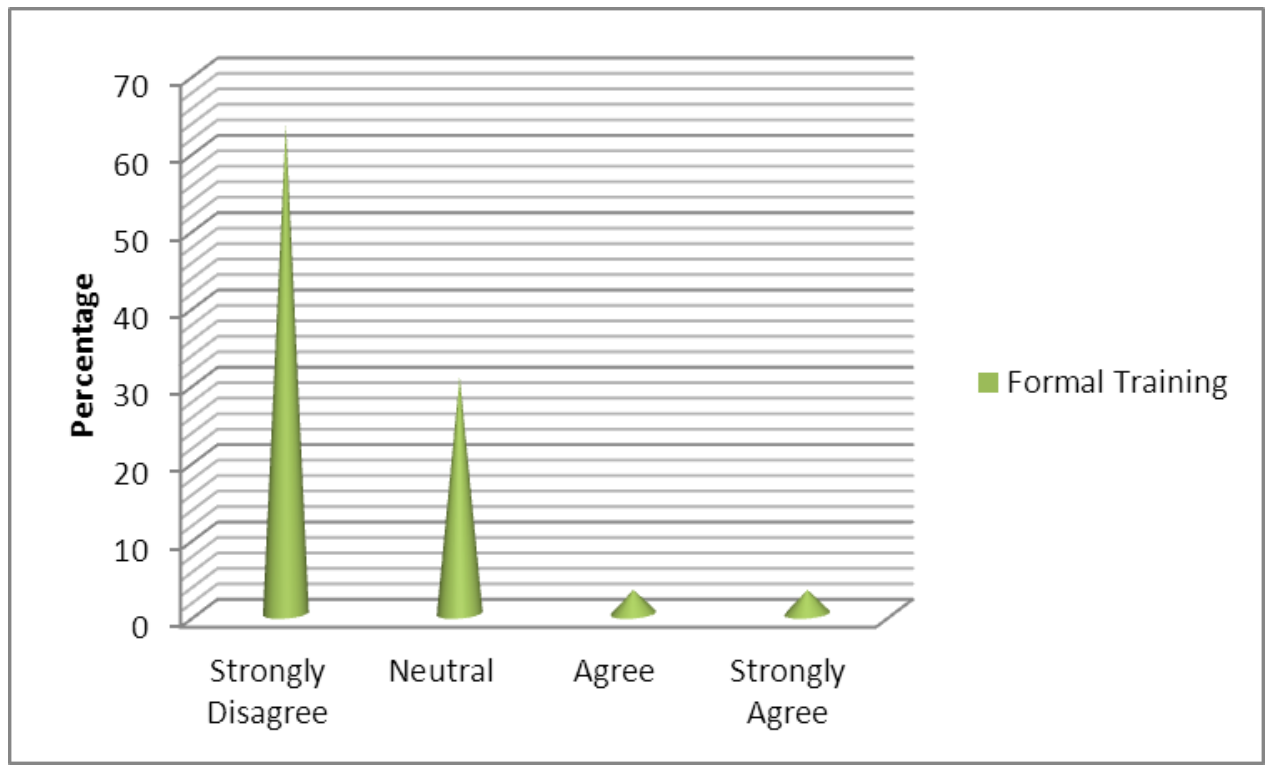

Figure 4 - 8: Formal Training

Source: Author (2012)

\subsubsection{Potential Successor}

According to the study $32 \%$ of total respondents, indicated that they had strongly disagreed to the fact that they have potential as a successor since they had management skills, $12 \%$ disagreed, 44\% were neutral, 9\% agreed and 3\% strongly agreed. From Figure 4-17 below of the study, it can be concluded that majority of the respondents are not certain if they have the right management skills to undertake another job as a potential successor. 


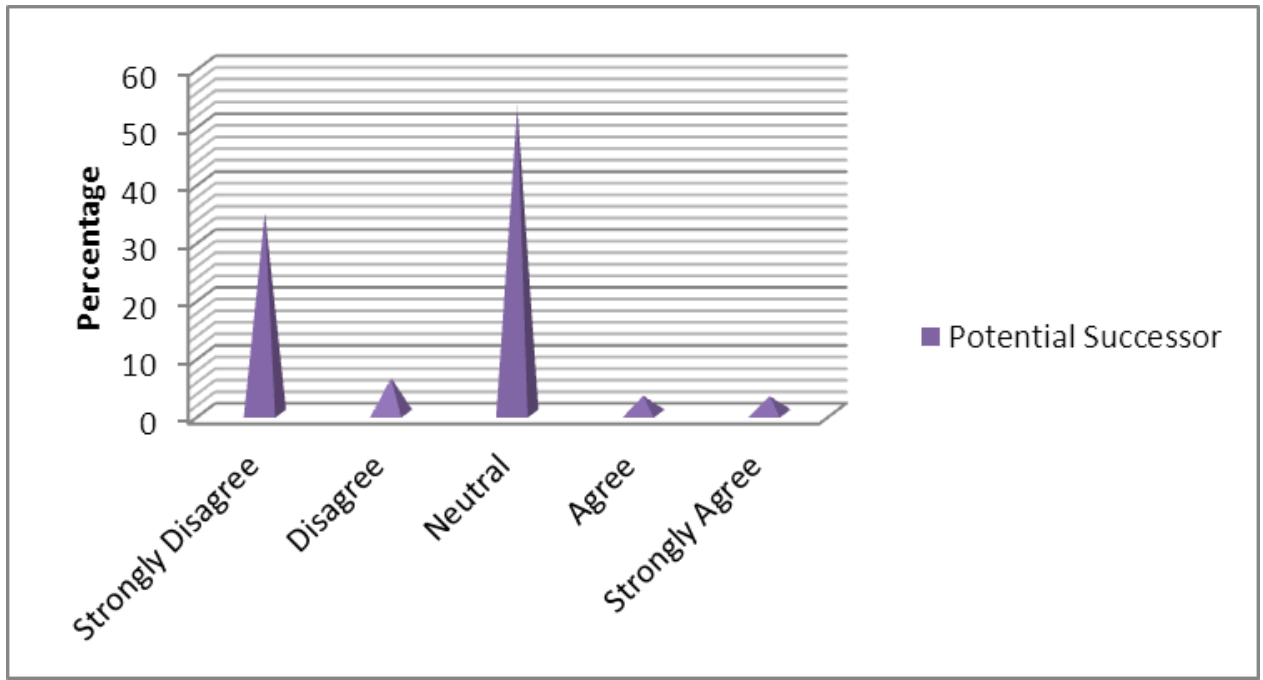

Figure 4 - 9: Potential Successor

Source: Author (2012)

\subsection{Summary of Findings, Conclusion and Recommendations}

\subsection{Summary}

This chapter focuses on the answers to the research questionnaires derived from the study. It also concludes the study and covers the summary of the findings and recommendations.

\subsubsection{Commitment, Knowledge and Skill of Successor}

The study revealed that the customers are not proudly associated with the business because of lack of customer relation skills. Majority of respondents have confidence in each other's business capabilities. Most SMEs prepare the person to take over the business when the current one retires. There are inadequate communication channels available in most businesses. Majority of the respondents do realize their business ambitions. Employees cannot be retained to work in the same business they were working for after securing another job elsewhere because of their personal objectives are not met. Most employees in SMEs do not view the type of business they are involved in as rewarding and hence would not want to venture in the same business in future. There are no formal/informal trainings offered to new managers prior to undertaking the assignment and majority of the respondents are not certain if they have the right management skills to undertake another job as a potential successor

\subsection{Conclusions}

\subsubsection{Succession Planning}

Most SMEs have a succession plan, replace the current owner/manager with a successor in good time, plan ahead for succession and customers do find it easy to get used to the new owner. 


\subsubsection{Commitment, Knowledge and Skill of Successor}

Most customers are not proudly associated with SMEs though majority of respondents have confidence in each other's business capabilities. Most SMEs prepare the person to take over the business when the current one retires and have inadequate communication channels. Most employees cannot be retained to work in the same business and do not view the type of business they are involved in as rewarding. There are no formal/informal trainings offered to new managers prior to undertaking the assignment and majority of the respondents are not certain if they have the right management skills to undertake another job as a potential successor.

\subsection{Recommendations}

\subsubsection{Succession Planning}

Most SMEs should have a succession plan in place and stipulate clearly how such plan will be executed or implemented. The government can have a policy governing this and follow up to ensure each SME has a succession plan in place.

\subsubsection{Commitment, Knowledge and Skill of Successor}

All successors should be trained and ensure that they have proper skills in place before they proceed over the predecessor to ensure continuity of the business. A good communication channel should be put in place to aid in flow of information to avoid conflicts.

\section{Acknowledgement}

I thank the Almighty God for the far He has brought me. I would like to acknowledge my supervisor who tirelessly encouraged, supported, guided, tutored and gave me valuable suggestions in ensuring the success of this project report.

My sincere gratitude to all the respondents during data collection, and to my family, colleagues and friends; Kate, Angela, Patrick, Sally, Beatrice, Mwanzia, Redempta, Martha, Emily, Stephen and Miriam among others for the great support they gave me.

I sincerely appreciate the support given to me by the department of Entrepreneurship and Procurement, Jomo Kenyatta University of Science and Technology.

\section{REFERENCES}

Bjuggren, P and Sund, L (2001) 'Strategic Decision Making in Integration Successions of Small and Medium Size Family-owned Business', Family Business Review 14 (1) 
Bowen, M., Morara, M. \& Mureithi, S. (2009). Management of Business challenges among small \& Micro enterprises in Nairobi- Kenya: KCA. Journal of Business Management vol. .2

Bridge, S., O'Neill, K., Cromie, S., (1998). Understanding Enterprise, Entrepreneurship and Small Business. London: McMillan.

Bryson, J. Wood, P. and Keeble, D. (1993). " Business Networks, Small Firm Flexibility and Regional Development in the U.K Business Services". Entrepreneurship and Regional Development , 5, 265-277.

Burt, R. (1992). "Structural holes: The Social Structure of Competition". Cambridge: Havard University Press.

Butler, R. (1980). Control through Markets, Hierarchies and Collectives. Paper Presented to European Group for Organization Studies Conference. London: Imperial College.

Butler, R. (1991). Designing Organizations: A Decision-Making Perspective. London: Routledge.

Butler, J. and Hansen, G. S. (1991). " Network Evaluation, Entrepreneurial Success, and Regional Development". Entrepreneurship and Regional Development , 3, 1-16.

Butler, R. and Sohod, S. (1995). Joint-Venture Autonomy: Resource Dependence and Transaction Cost Perspectives. Scandinavian Journal of Management , 11 (2), 159-175.

Central Bureau of statistics (1999). ICEG and K-REP, National MSE Baseline

Central Bureau of statistics (1999). National Micro and Small Enterprise Baseline survey results . Conducted by the Central Bureau of Statistics (CBS), International Centre for Economic Growth (ICEG) and K-REP holdings Ltd, Nairobi: Kenya.

Chu., P. (1996). Social Network Models of Overseas Chinese Entrepreneurship: The Experience in Hong Kong and Canada". Canadian Journal of Administrative Sciences , 13 (4), 358-365.

Chua, J. H., Chrisman, J. J. and Sharma, P. (1999) 'Defining the Family Business by Behavior', Entrepreneurship Theory and Practice 23(4): 19-39.

Cliffe, S. (1998) 'Facing up to Succession', Harvard Business Review 76(3): 16-18.

Coarse, R. (1937). "The Nature of the Firm". Economica.

Contribution to the US Economy: A Framework for Assessing Family Business Statistics', Family Business Review 9(2): 107-24. 
Curran, Jarvis, R. Blackburn, R. A and Black, S. (1993). " Networks and Small Firms: Construct Methodological Strategies and some Findings". International Journal of Small Business , 11 (2), 34 - 45. 